\title{
Cuestionando el SUJeto eStándar en DERECHO: ANÁLISIS CRÍTICO DE LOS CONCEPTOS MINORÍA Y MAYORÍA DE EDAD, NIÑO, MENORES Y ADOLESCENTES*
}

\section{QUESTIONING LAW'S STANDARD SUBJECT: A CRITICAL ANALYSYS OF THE AGES OF MINORITY AND MAJORITY, CHILDREN, MINORS AND TEENAGERS}

Sheila Fernández Míguez

Trabajo recibido el 03 de enero 2018 y aprobado el 10 de agosto de 2018

\section{Resumen}

En el presente estudio se analiza desde la perspectiva de la criminología y la epistemología feminista, qué papel ha jugado y juega la terminología como herramienta que define y construye derechos y deberes a la vez que olvida, criminaliza y/o margina a determinadas personas. En concreto, el estudio se centra en los conceptos empleados para nombrar al sujeto y regular etapas vitales fundamentales, niño, menor, infancia y adolescencia, partiendo del punto de inflexión etario de los 18 años que determina la menor y mayor edad que establece el marco internacional de la Convención de los Derechos del Niño de 1989.

Palabras clave: niño, menor, adolescencia, poder adulto, justicia juvenil y género.

\begin{abstract}
Adopting a perspective from both criminology and feminist epistemology this paper examines the role that terminology plays a as tool that defines and constructs rights and duties while at the same time neglects, criminalizes and/or marginalizes certain groups of people. More specifically, this paper focuses on the concepts deployed to name an individual and regulate her/his different life stages: child, minority, infanthood and adolescence, starting from the dividing line between adulthood and boy/girlhood that the age of 18 is as established by the 1989 Convention on the Rights of the Child.
\end{abstract}

Keywords: children, minor, teenager, age of licencense, juvenile justice and gender

* Sheila Fernández Míguez, Integrante del Equipo de Investigación Criminalidad, Psicología Jurídica y Justicia Penal en el siglo XXI de la Universidad de A Coruña.

Quiero agradecer muy especialmente a Luz María Puente Aba, por las correcciones y consejos en la redacción de este artículo. Para terminar, quiero hacer mención especial a Esther Pillado, directora del Máster en Menores en Situación de Desprotección y conflicto social, de la Universidade de Vigo, donde me perfeccioné en cuestionar el adultocentrismo 


\section{INTRODUCCIÓN}

Solo conociendo de dónde venimos, podemos saber dónde estamos, y eventualmente hacia dónde caminamos. En este sentido se manifiesta Iñaki Rivera ya en 1984 en su cita "sin el auxilio de la historia, la filosofía, la economía, la psicología o la antropología, por citar algunas de las disciplinas más relevantes que se tienen ocupado de esta cuestión, desconoceríamos, por ejemplo: la evolución y transformación de los sistemas punitivos; su vinculación con los sistemas de producción económica y el mercado laboral, los significados y valores que encierra y produce el castigo, las auténticas funciones que el mismo tiene desplegado, y su relación con las diversas formas-Estado"1.

Siguiendo este planteamiento interdisciplinar se parte de la siguiente pregunta de investigación, ¿cómo generan discriminación las categorías usadas por el ordenamiento jurídico para referirse a la niñez y adolescencia? La hipótesis de trabajo es que esta discriminación surge principalmente al invisibilizar vidas, o visibilizarlas de forma interesada, desde un paradigma adultocéntrico. Para ello fijamos el siguiente objetivo, conocer cómo han evolucionado y las implicaciones sociales y jurídicas de las categorías: minoría de edad, mayoría de edad, niño, menores y adolescentes, al tratarse de términos clave en la regulación de la vida de las personas con menos de 18 años. En esta investigación, se ha trabajado con una metodología mixta, donde combinamos el uso de la epistemología feminista y el análisis jurídico comparado entre Chile y España. Advertimos en este punto, que no se tendrán en cuenta las justicias de los diferentes pueblos originarios que habitan Chile. Y en último lugar se presentan las conclusiones de la investigación.

\section{LEVANTANDO EL VELO. UN ANÁLISIS CRÍTICO DE LOS CONCEPTOS: MINORÍA Y MAYORÍA DE EDAD, NIÑO, MENORES Y ADOLESCENTES}

\subsection{Minoría y mayoría de edad}

Históricamente por diversas razones más relacionadas con el aspecto civil que penal/criminal se ha regulado cuándo un ser humano era "jurídicamente persona" y su gradual acceso a derechos y deberes. Superadas muchas de las construcciones históricas, a día de hoy se considera, siguiendo la Teoría vitalista, tanto en España en el art. 30 del Código Civil español, (en adelante CCE) como en Chile en el art. 74 del Código Civil chileno (en adelante CCC), que existe personalidad jurídica cuando una persona está desprendida del vientre materno. Es decir, es suficiente un destello de vida para constituirse en persona.

Tener personalidad jurídica nos configura como seres humanos sujetos de derechos, los cuales podremos ejercer en el futuro, de forma progresiva, hasta el ejercicio total de los mismos, transcurridos dieciocho años. Es esta cifra la que marca en la actualidad el punto de inflexión entre la minoría y la mayoría de edad. En este sentido la legislación interna de cada país tiene un por qué a los 18 años.

\subsubsection{España}

En España la mayor edad a los dieciocho años se implementa en 1978. Antes de esa fecha, la mayoría de edad se adquiría a los veintiún años, y su regulación estaba dispersa en el Código Civil español y

1 Riveira (2003), p. 84.

FERNÁNDEZ MíGUEZ, Sheila. Cuestionando el sujeto estándar en derecho: análisis crítico de los conceptos minoría y mayoría de edad, niño, menores y adolescentes. Revista Justicia y Derecho, Santiago, v. 1, n 1, 2018 
diversos derechos civiles propios.

El año 1978 es clave dentro de la historia contemporánea española. El mismo forma parte del periodo denominado transición democrática (aproximadamente, del 20 de noviembre de 1975, muerte del dictador Francisco Franco, al 29 de diciembre de 1978, entrada en vigor de la Constitución)². Este periodo estuvo marcado por grandes pactos entre los grupos de poder, que diseñan e implementan reformas legales con el objetivo de convertir España en un Estado social y democrático de derecho. Y para ello hacía falta que la gente pudiese votar y aprobar una Constitución. El primer paso para lograr dicho objetivo fue la aprobación de la Ley 1/1977, de 4 de enero, para la Reforma Política ${ }^{3}$, conocida como la octava Ley política del Reino, para la Reforma Política, que fue sometida a referéndum el 15 de diciembre del mismo año, donde solo pudieron participar personas mayores de veintiún años. La importancia de esta ley era mayúscula dado que establece que las Cortes se componen de Diputados que serán elegidos por sufragio universal, directo y secreto de los (y las) españoles (las) mayores de edad (artículo segundo dos). Es en este punto, donde tocará definir qué se entiende por mayor de edad, tarea que no será sencilla, dado que en España existen diferentes derechos civiles que regulan la mayoría de edad.

Es necesario tener en cuenta que en España son de primera aplicación los derechos propios, y solo cuando estos no tengan disposición al respecto se aplicará el Código Civil Español, de forma que este último actúa como derecho supletorio en algunos territorios. En este sentido reducir la mayoría de edad a dieciocho años y homogeneizar los derechos y deberes exigía diferentes reformas legales, dado que Aragón y Navarra tenían derecho propio que regulaba esta materia, y establecía la mayoría de edad en los veintiún años, misma edad que fijaba el Código Civil.

Las normas que se aprobaron con el propósito de establecer la mayor edad en los 18 años, fueron, en primer lugar, el Real Decreto-Ley 33/1978, de 16 de noviembre, sobre mayoría de edad', que homogeneiza la mayoría de edad en los dieciocho años. Esta norma modifica el Código Civil y la Compilación de Derecho Civil de Aragón y recoge una disposición adicional segunda para el caso del Derecho Civil Especial Navarra. Sin embargo, la misma no fue suficiente, y se hizo necesario un segundo Real Decreto-ley 38/1978, de 5 de diciembre por el que, de acuerdo con la excelentísima Diputación Foral de Navarra5, se modifica la Ley 50 de la Compilación de Derecho Privado Foral de Navarra, el cual entró en vigor el mismo día de su publicación, el 5 de diciembre de 1978. Es a partir de este momento, cuando en todos los territorios que conforman el reino de España, las personas serán consideradas mayores de edad a los dieciocho años. La urgencia y la motivación de adoptar en tan corto plazo estas normas respondió a una estrategia política, diseñada en función de las cifras que en esa época se manejaban. Dar derecho al voto a personas a partir de los dieciocho años, incrementaba el censo del referéndum para la aprobación de la Constitución. Importante, dado que los datos estadísticos de la época indicaban que la gente joven se posicionaba mayoritariamente a favor del texto constitucional, como se demostró en el referéndum del 6 de diciembre de 1978, por el que se aprobó dicha Constitución.

2 En relación con el contexto histórico, existe consenso en entender que la transición española se inicia con la muerte del dictador Francisco Franco el 20 de noviembre de 1975, y se prolonga hasta la aprobación de la Constitución en diciembre de 1978. Si bien, la historiografía especializada discute las fechas antes mencionadas.

3 Ley 1/1977, de 4 de enero, para la Reforma Política. Boletín Oficial del Estado, № 4, de 5 de enero de 1997, páginas 170 a 171. Derogado. Disponible en https://boe.es/buscar/doc.php?id=BOE-A-1977-1965 [fecha de consulta: 01.07.2016].

4 Real Decreto-Ley 33/1978, de 16 de noviembre sobre mayoría de edad, B.O.E. núm. 275, del 17 de noviembre de 1978. Vigente. Disponible en https://www.boe.es/buscar/doc.php?id=BOE-A-1978-28627 [fecha de consulta: 01.07.2016].

5 Real Decreto-Ley 38/1978, de 5 de diciembre por el que, de acuerdo con la excelentísima Diputación Foral de Navarra, se modifica la Ley 50 de la Compilación de Derecho Privado Foral de Navarra, B.O.E núm. 291, de 6 de diciembre de 1978, página 27588. Vigente. Disponible en https://www.boe.es/diario_boe/txxt.php?id=BOE-A-1978-29748 [fecha de consulta: 01.07.2016].

FERNÁNDEZ MíGUEZ, Sheila. Cuestionando el sujeto estándar en derecho: análisis crítico de los conceptos minoría y mayoría de edad, niño, menores y adolescentes. Revista Justicia y Derecho, Santiago, v. 1, n 1, 2018 


\subsubsection{Chile}

En Chile será necesario esperar hasta el 1 de junio de 1993, cuando se publica la Ley 19.221 que establece la mayoría de edad a los 18 años y modifica los cuerpos legales que indica ${ }^{6}$. En este sentido, la reducción del acceso a la mayor edad no tuvo que ver con las votaciones de transición de dictadura a democracia, sino con un compromiso internacional incumplido, y ello porque Chile ratifica la Convención sobre los Derechos del Niño el 14 de agosto de 19907.

\subsubsection{Convención sobre los Derechos del Niño}

En el plano internacional, la mayoría de edad se define en oposición a la minoría de edad. A esta conclusión se llega a través de la Resolución 44/25, de 20 de noviembre de 1989, conocida como Convención Sobre los Derechos del Niño ${ }^{8}$, en adelante CDN, la cual establece en su artículo primero: Para los efectos de la presente Convención, se entiende por niño todo ser humano menor de dieciocho años de edad, salvo que, en virtud de la ley que le sea aplicable, haya alcanzado antes la mayoría de edad. En cumplimiento de dicho precepto, se iguala para todos los países parte la minoría y mayoría de edad. Así de los 0 hasta los 18 años, las personas serán denominadas niños y a partir de esa edad, las pasarán a ser consideradas mayores de edad.

En esta Convención se reconocen por vez primera derechos civiles a la niñez y adolescenciaª. Conviene tener presente que la CND está ratificada por todos los países del mundo, a excepción de Estados Unidos $^{10}$. Ello no implica que todos los países firmantes la respeten; en efecto, como consecuencia de lo anterior, es considera la Convención que más violaciones ha sufrido.

\subsection{Niño}

Si analizamos la voz"niño" según la Real Academia de la Lengua Española, diremos que estamos ante un adjetivo, masculino, singular. Y entre otras acepciones puede hacer referencia a alguien que está en la niñez, o que tiene pocos años, o poca experiencia. También indica el diccionario que puede usarse para referirse a una persona que obra con poca reflexión o con ingenuidad ${ }^{11}$. Ahora bien, es necesario hacer referencia a los textos que han ocupado tradicionalmente esta voz en el ámbito del Derecho para conocer las connotaciones sociales y jurídicas que han acompañado al concepto.

La legislación española (en su diversa normativa, legislación estatal, autonómica y municipal) tradicionalmente se ha inclinado por el uso de niño para la legislación relativa a la protección (protección que

6 Ley 19.221 de 1993.

7 Véase unicef.cl (en línea). Disponible en http://unicef.cl/web/convencion-sobre-los-derechos-del-nino/ [fecha de consulta: 03.07.2016].

8 Adoptada y abierta a la firma y ratificación por la Asamblea General en su resolución 44/25, de 20 de noviembre de 1989. En España entró en vigor el 31 de diciembre de 1990, y en Chile el 2 de septiembre de 1990.

9 Véase, Dávila y Naya (2006), p. 72.

10 Sudán del Sur en mayo de 2015 y Somalia en octubre de 2015 fueron los últimos países en suscribir la Convención de los Derechos del Niño, convirtiéndose en el Estado 195 y 196 respectivamente, en ratificar dicho tratado. Estados Unidos es por tanto el único país del mundo en el que la Convención no es aplicable, dado que dicho estado solamente ha firmado la Convención en 1995, pero aún no la ha ratificado, por lo que no es aplicable en dicho territorio. Uno de los principales motivos o justificaciones para la no ratificación es, la prohibición expresa de pena de muerte por hechos cometidos en la minoría de edad, que es legal en alunas zonas de Estados Unidos. Véase, Centro de Noticias ONU, www.un.org/spanish/News/story.asp?NewsID=33493 [fecha de consulta: 04.07.2016]; Unicef, www.unicef.org/spanish/media/media_81776.html [fecha de consulta: 04.07.2016].

11 Cfr. Diccionario de la Lengua española. Disponible en http://dle.rae.es/id=QW5mMvv [fecha de consulta: 01.07.2016].

FERNÁNDEZ MíGUEZ, Sheila. Cuestionando el sujeto estándar en derecho: análisis crítico de los conceptos minoría y mayoría de edad, niño, menores y adolescentes. Revista Justicia y Derecho, Santiago, v. 1, n 1, 2018 
durante años se puede asimilar también a corrección/punición). Sin embargo, la diferencia en el uso de niño o menores (más frecuente este segundo en el ámbito del Derecho penal actual) no es taxativa, puesto que es posible encontrar leyes que, con la intención de proteger, se refieren al sujeto de protección con el término menor ${ }^{12}$, que será abordado en el siguiente epígrafe. Un ejemplo claro de esta tendencia del legislador de destinar la categoría niño al ámbito de protección, es la Ley Orgánica 13/1995, de 18 de diciembre, sobre la modificación de la Ley Orgánica General Penitenciaria, la cual regula la permanencia de niños (niñas y niñes) ${ }^{13}$ dentro del recinto penitenciario hasta la edad de la escolarización obligatoria $(4 \text { años })^{14}$, para que permanezcan con sus madres en condiciones de privación de libertad. Los hombres carecen del derecho a la paternidad dentro del recinto penal. Sin embargo, cuando ese niño (niña, niñe o adolescente) es responsable penal, el legislador se decanta por el uso de menores como se evidencia en la Ley Orgánica 5/2000, de 12 de enero, Reguladora de la Responsabilidad Penal de los menores (en adelante LORPM).

La tendencia actual en España se inclina por el uso de conceptos como infancia, menores, adolescencia y también en el ámbito de la legislación regional europea el uso de niños, como un concepto más inclusivo de las distintas pluralidades. En este sentido conviene señalar como precedente el uso de niños del artículo 49 CE, -utilizado por el legislador constitucional, sin ser consciente, probablemente, de la carga significativa que aporta una letra, la "s"-, el cual en su apartado 4 indica, Los niños gozarán de la protección prevista en los acuerdos internacionales que velan por sus derechos. En este sentido consideramos que se puede establecer una analogía entre el concepto niño-niños (niña/s y niñe/s) y mujer-mujeres. Y ello porque las investigaciones y críticas postmodernas a la ciencia que se han desarrollado desde los años 80 por la epistemología feminista, concretamente Donna Haraway y Susan Herkman, han rechazado la categoría analítica de mujer (en singular), sosteniendo que es necesario hablar de mujeres, en plural, en

12 Véase en relación al uso de menores en normas relativas a protección en España, las siguientes leyes: Real Orden de 2 de enero de 1930, por la que se prohíbe la asistencia a menores de 14 años a toros y boxeo; Ley 1/1997, de 7 de febrero, de atención integral a los menores; Ley 1/2006, de 28 de febrero, de Protección de Menores de La Rioja; Ley Orgánica 11/2015, de 21 de septiembre, para reforzar la protección de las menores y mujeres con capacidad modificada judicialmente en la interrupción voluntaria del embarazo; Circular 6/2015, de la Fiscalía, sobre aspectos civiles de la sustracción internacional de menores.

13 Incluimos entre paréntesis las voces niñas y niñes, porque si bien la norma no las menciona directamente consideramos que es importante que se visualicen y estén en la mente e imaginario de la persona que lee este texto, y ello porque ponen en evidencia que el legislador no las tuvo en cuenta y tampoco sus necesidades.

El término "niñe" es un concepto más reciente, el mismo surge desde diversos movimientos sociales de defensa de los derechos de las personas transexuales, transgénero, travestis e intersex, puede consultarse en este sentido el trabajo realizado por la asociación Organizando Trans-Diversidades, OTD, en concreto su biblioteca en línea, accesible en http://otdchile.org/biblioteca-otd/ donde se puede encontrar diversos textos que apuestan por designar el género con "e", ejemplo de ello es la editorial del no1 de su revista Le Trans. En mi opinión, el uso de este, podríamos decir nuevo género gramatical, presenta como ventajas estar nombrando a todas aquellas personas que no encajan en la etiqueta binaria, en este caso niña/niño junto con una escritura de fácil lectura y estéticamente ordenada. He preferido está formula frente al uso del diminutivo "trans" que hace referencia a las categorías antes indicadas, porque niñe permite visibilizar precisamente un momento vital más temprano, donde se están definiendo todavía muchos rasgos de la persona y pone en valor esta etapa de la vida, de por sí invisibilizada y las problemáticas propias que estas personas y sus familias padecen. Estos argumentos también me han llevado a descartar las fórmulas que se contienen en el libro colectivo Derechos humanos, diversidad sexual y políticas públicas en América Latina (2015). En esta obra, Andrés Rivera, autor del Capítulo XII, "Derechos civiles de la población trans (transgénero, travesti, transexuales e intersex)" se decanta por el uso de niñas, niños y adolescentes (NNA), dado que no cumple con los requisitos de economía del lenguaje, y además invisibiliza la realidad trans, que queda oculta en el término adolescencia, el cual psicológicamente denomina una etapa diferente de la vida de la persona. Por su parte, el Capítulo VIII “Niños, niñas y adolescentes diversos/as" fue elaborado por Felipe Villarreal y Alejandra Vallejos, quienes ocupan la expresión Niños, niñas y adolescentes que también resumen en NNA acompañada de las siglas LGBT. Esta fórmula tampoco me parece adecuada, dado que dificulta la lectura con un número de siglas innecesario, que además no termina de visibilizar en mi opinión la realidad trans, y a mayores produce una sexualización temprana de la niñez, con las categorías Lesbiana, gay y bisexual.

14 En Chile, la edad hasta la que una madre privada de libertad puede permanecer con sus crianzas, es hasta los dos años. Produciéndose una fractura temprana del vínculo entre madre y crías. Cuando estas mujeres, en situación de encierro no tiene familia o personas en el exterior, será el SENAME (Servicio Nacional de la Infancia) quien se haga cargo de su hija, hije o hijo.

FERNÁNDEZ MíGUEZ, Sheila. Cuestionando el sujeto estándar en derecho: análisis crítico de los conceptos minoría y mayoría de edad, niño, menores y adolescentes. Revista Justicia y Derecho, Santiago, v. 1, n 1, 2018 
atención a la fragmentación infinita de perspectivas. Entienden las autoras, criticando los postulados del "punto de vista" en relación al concepto de mujer, que la búsqueda de una voz y una visión de la mujer es otra forma de pensamiento androcéntrico que insiste en decir sólo una verdad o historia acerca de la realidad. En este sentido el rol de las experiencias de mujeres es central para las feministas postmodernas y apuestan por entender que las experiencias de las mujeres son diferentes dado que están cruzadas por las variables de edad, clase, raza, etnia y cultura entre otras. En este sentido la investigación feminista ha de tomar estas variables en cuenta y no reprimir las diferencias. Es desde este planteamiento que se evoluciona del concepto mujer en singular al concepto mujeres en plural. Siguiendo esta teoría, entendemos que se debe hablar también de niños, niñes y niñas en aras a reconocer las diferentes infancias que existen y formas de vivirlas ${ }^{15}$.

En la legislación chilena también se aprecia el uso de diversos conceptos: niño, niñez, adolescentes o menores. No obstante, el concepto de niño tiene una presencia más marcada, que llega hasta nuestros días. Y por ello se instala con más fuerza como equivalente de hombre, que se encuentra regulado en el 25 CCC.: Las palabras hombre, persona, niño, adulto y otras semejantes que en su sentido general se aplican a individuos de la especie humana, sin distinción de sexo, se entenderán comprenden ambos sexos en las disposiciones de las leyes, a menos que por la naturaleza de la disposición o el contexto se limiten manifiestamente a uno solo. Este precepto introduce una regla de interpretación en cuanto al género donde se instaura el masculino como sujeto tipo en derecho. Continua el precepto diciendo, por el contrario, las palabras mujer, niña, viuda y otras semejantes, que designan el sexo femenino, no se aplicarán al otro sexo, a menos que expresamente las extienda la ley a él.

Sin embargo, si analizamos dicho adjetivo críticamente con ojos de jurista y perspectiva de género, debemos advertir, en primer lugar, que sobre el mismo se construye una ficción que el Derecho "legaliza". En este sentido, ya no hablamos de adjetivo, sino de concepto jurídico en el cual se incluye el femenino y el masculino. Se hace evidente que la construcción de conceptos supuestamente neutros se instala también en las categorías creadas para hacer referencia a las edades más tempranas de vida. De esta forma y continuando con el juego de analogías o equivalencias, antes propuesto, podemos hacer lo mismo entre los conceptos de niño y hombre. Analizando nuestro concepto de niño(s), siguiendo las críticas elaboradas por la epistemología feminista, las cuales ponen de manifiesto que no existen conceptos neutros ni tampoco el hombre universal. Se evidencia así, que la construcción científica fue elaborada por el hombre blanco, burgués, occidental y heterosexual, condicionado por una determinada ideología y experiencia. En consecuencia, solo trato de dar respuesta a las preguntas y necesidades que este sujeto necesitó responder. Este descubrimiento hizo visible que la ciencia, incluida la jurídica, ha excluido a las mujeres y por ende a las niñas y niñes (también sesgadamente a adolescentes) no solo como agentes del conocimiento, sino también de la oración social y legal, eliminándolas del imaginario. A este fenómeno que todavía está presente en la sociedad Rosi Braidotti lo denomina falogocentrismo ${ }^{16}$, y viene a completar lo ya teorizado por Kate Millett en su tesis doctoral, cuando afirmaba la existencia de una ideología adultocéntrica.

En conclusión, en primer lugar, como consecuencia de lo apuntado cabe afirmar que, cuando se elimina del imaginario un tipo de sujeto, se deja de legislar para él y se produce un efecto invisibilizador de los seres humanos, sobre todo de aquellos que no encajan dentro del sujeto considerado neutro. En este sentido, la categoría niño como sujeto de derechos al que se refieren las diferentes normas, producen un efecto invisibilizador de personas que no encajan dentro de este término, y en consecuencia oculta vidas

15 Para más información al respecto consúltese Araiza (2012).

16 Ibidem. Cfr. p. 166. Rosi Braidotti -según Araiza Días- hace referencia en el contexto de occidente al hábito que consiste en referirse tanto a la subjetividad como a todos los atributos clave del sujeto pensante en términos de masculinidad. 
que son omitidas en la realidad jurídica, especialmente las niñas, niñes y adolescentes.

En segundo lugar, los estudios que se han realizado con perspectiva de género, han demostrado que las categorías masculinas no son conceptos neutros. Un ejemplo de que estos estudios junto con la sociedad civil tienen cada vez más influencia, es la tendencia de incluir niños y niñas ${ }^{17}$, el concepto niñez ${ }^{18}$, o adolescentes, en las normas más recientes. Terminología esta última más respetuosa con la pluralidad y diversidad que también son variables aplicables a las personas menores de dieciocho años; sobre todo, a la hora de fundamentar legislaciones con miras en las identidades culturales, de género o sexuales. Si bien se van conquistando ciertos logros, aun no podemos hablar de que se haya implementado esta terminología inclusiva en el ADN del legislador ni español ni chileno. En relación a este último es muy significativo lo que está sucediendo con el Proyecto de Ley del Sistema de Garantías de los derechos de la niñez, de 24 de septiembre de 2015, Boletín 10315-18 ${ }^{19}$, que si bien desde la propuesta del ejecutivo partió con una mirada más inclusiva en relación a los conceptos a los que nos referimos, a lo largo de los trámites parlamentarios la ha ido perdiendo; así, a 13 de julio de 2016, el nombre que consta es Proyecto de Ley, Sistema de Garantías de los derechos del niño y adolescentes, si bien no sabemos cómo vaya a quedar finalmente, dado que todavía está en proceso de discusión.

Y en tercer y último lugar, en las legislaciones de ambos países se establece una diferencia, aunque no del todo estable, en el uso del lenguaje, inclinándose por los conceptos de niño y niña, infancia o niñez para normas relativas principalmente a la protección, salud o educación y se reserva el concepto de menores o adolescentes ${ }^{20}$ para el ámbito penal ${ }^{21}$.

\subsection{Menores}

La RAE recoge ocho acepciones del adjetivo menor. En este sentido, interesan a este estudio las cuatro primeras, 1. adj. que es inferior a otra cosa en cantidad, intensidad o calidad. 2 adj. Menos importante con relación a algo del mismo género. 3. Dicho de una persona: Que tiene menos edad que otra. 4. adj. menor de edad (dicho de una persona que no ha alcanzado la mayoría de edad22.

Las conclusiones que se derivan de estas acepciones son bastante ilustrativas, y en efecto hablando del género humano, las personas menores son menos en cantidad que las mayores de edad, sobre todo en los países enriquecidos. Si nos situamos desde el contexto de los derechos, también diremos que su tratamiento no ha tenido la misma importancia que los derechos de las personas mayores, ni gozan de

17 Véase, en relación con el uso de niños y niñas en Chile, la Ley 20.558 de 7 de enero de 2012, que Establece el día del niño y niña prematuros;

18 Véanse entre otras las siguientes normas en relación al uso del concepto niñez en Chile: Ley 20.032, del 2 de julio de 2005, que Establece sistema de atención a la niñez y adolescencia a través de la red de colaboradores del Sename, y su régimen de subvención; Decreto- 230, de 12 de agosto de 2006, que Promulga el Convenio de Cooperación sobre asistencia a la niñez y a la adolescencia entre la República de Chile y la República de Ecuador; Decreto 105, de 14 de agosto de 2012, que Modifica Decreto No841, de 2005, que aprueba Reglamento de la Ley № 20.032, que establece un sistema de atención a la niñez y adolescencia a través de la red de colaboradores acreditados del servicio Nacional de menores, y su régimen de subvención.

19 Proyecto de Ley, Sistema de Garantías de los derechos de la Niñez, de 24 de septiembre de 2015. Núm. Boletín 10315-18. Cámara de Diputados, Comisión de Familia y Adulto Mayor. Puede seguirse la tramitación de la ley en https://www.camara.cl/ pley/pley_detalle.aspx?prmID=10729\&prmBL=10315-18

20 Véase, en relación al uso de adolescentes en Chile la Ley 20.084, de 7 de diciembre de 2005, que Establece un sistema de responsabilidad de los adolescentes por infracciones a la Ley Penal.

21 En relación con el uso del concepto menores en el ámbito penal puede verse: Proyecto de ley núm. 10784-07 de C. Diputados, de 5 de julio de 2016 (modifica el Código Penal para establecer la imprescriptibilidad de la acción penal y de la pena tratándose de delitos sexuales, de tráfico ilícito de migrantes y de trata de personas, cometidos contra menores de edad).

22 Cfr. Diccionario de la Lengua española (en línea). Disponible en http://dle.rae.es/?id=Ouc027t [fecha de consulta: 13.07.2016].

FERNÁNDEZ MíGUEZ, Sheila. Cuestionando el sujeto estándar en derecho: análisis crítico de los conceptos minoría y mayoría de edad, niño, menores y adolescentes. Revista Justicia y Derecho, Santiago, v. 1, n 1, 2018 
los mismos derechos. En este sentido, es muy ilustrativo conocer el contexto histórico en el que surge el concepto, cómo la cultura jurídica española y chilena lo han adoptado, y asimismo el conflicto terminológico que surge de las traducciones de Convenios o Tratados Internacionales, que será abordado en el último apartado del epígrafe.

\subsubsection{Origen histórico}

Es necesario tener en cuenta el contexto histórico del concepto para comprender la carga simbólica que el mismo contiene. Siguiendo a Ágata María Sanz Hermida la expresión justicia de menores tiene sus orígenes en la creación del primer Tribunal para infancia en la ciudad de Chicago (Illinois, USA) en 1899 denominado Children's Court of the Cook Country, y en el empleo en los Estados de Rhode Island, Massachusetts e Indiana de la doctrina denominada del parens patriae, según la cual se autorizaba a sus respectivos órganos legislativos a la protección de la infancia "como haría un padre con sus hijos"23. Esta normativa pretendía dar una solución a la situación social que se vivía en ese momento en la ciudad de Illinois, en la que se había producido una rápida y fuerte industrialización y como consecuencia muchas niñas, niñes y niños fueron abandonados y delinquen para sobrevivir. Esta situación creó una sensación de falta de control sobre la niñez y nació un movimiento femenino denominado Salvadora de los Niños. Este movimiento puede encuadrarse dentro de la Teoría Positivista correccionalista, que Jordi Cabezas adjetiva como "de paternalismo dudoso y bastante reaccionario"24. Este colectivo pretendía rescatar a las criaturas delincuentes de las prisiones comunes y presentarlas ante tribunales especiales para ser juzgadas por leyes también especiales. Esto creó una mezcla heterogénea de personas recluidas. Cabe indicar que los métodos que implantaron estas leyes fueron educación, trabajo y aplicación de medidas correctoras por el tiempo necesario, lo que introdujo una indeterminación en la duración de la reclusión y a mayores una similitud entre medidas y las verdaderas penas. En relación a la efectividad de la pena como medida educadora o rehabilitadora, quiero apuntar, siguiendo con el ejercicio comparativo de estudios realizados para personas adultas, en primer lugar, que cuando no existe un horizonte de salida o término, la pena o medida es considerada cruel e inhumana. Y, en segundo lugar, en relación al debate sobre la resocialización de las penas como postulado orientador y legitimador de la pena de prisión, y del sistema penal en general, se afirma por parte de la doctrina especializada que ha fracasado en relación a las personas mayores de edad ${ }^{25}$. Sin embargo, el discurso de la resocialización está muy presente en las normas penales adolescentes; ejemplo de ello es en el contexto español la Ley Orgánica 5/2000 de 12 de enero, Reguladora de la responsabilidad penal de menores, (LORPM), la cual introduce el concepto de medidas-educativas, en sustitución del concepto penas. Y en tercer y último lugar, y ya desde los estudios centrados en niñez y adolescencia, hay que tener en cuenta que al tratarse de épocas de suprema importancia en la construcción de la personalidad, el tiempo de reclusión tiene unas consecuencias mucho más graves que para una persona adulta y es vivido de forma más dramática por quien sufre el encierro, dado que el paso del tiempo es percibido de forma diferente.

\subsubsection{España}

En el Estado Español las primeras legislaciones, regulan de forma conjunta infancia, control penal y mendicidad. Con la aproximación histórica a la terminología podemos ver la evolución que a este respec-

23 Cfr. Hermida, Sanz, Ágata (2002), p. 24.

24 Cfr. cabezas (2011), p. 160.

25 Véase, Brandariz (2014).

FERNÁNDEZ MíGUEZ, Sheila. Cuestionando el sujeto estándar en derecho: análisis crítico de los conceptos minoría y mayoría de edad, niño, menores y adolescentes. Revista Justicia y Derecho, Santiago, v. 1, n 1, 2018 
to se ha producido. Así a partir de 1904 se implanta el concepto de infancia ${ }^{26}$ con la promulgación de la primera ley española de Protección de la Infancia. De esta ley se derivó en 1908 la creación de las Juntas Provinciales y Locales de Protección de la Infancia y el Consejo Superior de Protección de la Infancia y Represión de la Mendicidad. Este organismo impulsó la promulgación de la Ley de Bases de 2 de agosto de 1918 y el Decreto Ley de 25 de noviembre del mismo año, sobre la creación y funcionamiento de los Tribunales para Niños. Estos estaban compuestos por un juez y dos vocales, y se establecieron paulatinamente en todas las capitales de provincia, creándose el primero de ellos en Bilbao en 1920. En 1925 se reorganizan y reciben el nombre de Tribunales Tutelares para Niños, nombre que se cambia en 1929, con la creación bajo el amparo de la misma normativa del Tribunal Tutelar de Menores, también en la ciudad de Bilbao. Es necesario tener presente, que esta ciudad comparte un contexto social, similar al de Illinois, al estar inmersa en un proceso de fuerte industrialización. Como muestra de que la legislación sobre niñez y adolescencia no ha sido prioridad en el contexto español, sirve de ejemplo conocer que la Ley de Bases de 2 de agosto de 1918 que regula la administración de justicia aplicada en la infancia y adolescencia, estuvo vigente parcialmente hasta el año 1992. Siguiendo a Cabezas podemos decir que "estas leyes encajan dentro del positivismo, y consagran dos figuras centrales el niño, en situación de peligro moral y material a saber, el niño abandonado el niño delincuente términos que finalmente se harán sinónimos"27.

Estas personas serán objeto privilegiado de intervención. Sometidas a tutoría y corregidas, bajo este pretexto se construyen las políticas de control dominante en aquellos años, es decir, el régimen de tutelas y el nacimiento del modelo correccional. Este modelo se articula para abandonar y tratar a estas personas, a estas crías $^{28}$ que dejan de serlo en el preciso momento, en que son escogidas para ser tutorizadas, protegidas por el Estado y por instituciones de beneficencia. Por efecto de esta selección se convertirán en menores, término que arrastra una carga peyorativa al relacionar pobreza, falta de moral y delincuencia. A mayores no construye un relato histórico verídico en relación al género -como sucede también con el término niño-. Es necesario enfatizar que, existía un trato diferenciado en cuanto al sexo-género al que perteneciese la persona a ser institucionalizada, así sobre las niñas pobres se permitían abusos, se aplicaban más encierros religiosos dirigidos a corregir sus conductas supuestamente pecaminosas. Mientras que los encierros aplicados a niños tenían otras características y habitualmente no estaban basados en la infracción de la norma moral29.

Este trato diferenciado queda ocultado en el concepto de menores, que produjo y produce todavía hoy una invisibilización de las prácticas aplicadas a una parte de las personas que fueron y son sometidas a la administración de justicia. Como ya se ha indicado, el uso de la terminología masculina muestra una historia donde el sujeto protagonista es varón blanco, indistintamente de su edad, y lo coloca como el individuo histórico estándar. En este sentido, como indica Cámara Arroyo, son aun minoritarios los estudios sobre criminalidad infantil femenina, que se inician a finales de los años 60 del siglo pasado ${ }^{30}$.

En la actualidad el concepto de menores en España lo encontramos en las normas que se dictan para regular la vida de las personas con menos de 18 años. Es un concepto jurídico que se aplica a un grupo concreto de personas, aquellas que se relacionan o debutan en el sistema de alguna u otra forma. Cuando los operadores no jurídicos hablan de menores están aportando una información añadida, indican

26 Para más información véase, "Censo guía de archivos de España e Iberoamérica”. Disponible en http://censoarchivos.mcu. es/CensoGuia/fondoDetail.htm?id=810815.

27 Cfr. Cabezas Salmerón, ob. cit., p. 163.

28 En la acepción de la RAE, de personas que se están criando. crío, a. (De cría).1. m. y f. Niño que se está criando.

29 No se hace referencia al tratamiento para niñes, pero se puede intuir, dado el contexto y otros estudios, la discriminación y correcciones que estas personas pudieron sufrir.

30 Cfr. Cámara Arroyo (2011), p. 335.

FERNÁNDEZ MíGUEZ, Sheila. Cuestionando el sujeto estándar en derecho: análisis crítico de los conceptos minoría y mayoría de edad, niño, menores y adolescentes. Revista Justicia y Derecho, Santiago, v. 1, n 1, 2018 
que son personas jóvenes que se encuentran en situación de conflicto, desprotección o son delincuentes. De este modo, colocan el estigma de la institucionalización o criminalizan a unas personas sobre las que tendría que invertirse todos los esfuerzos posibles en aras al consagrado interés superior recogido en el art.5 de la CDN. Es por ello, que se hace necesario recurrir a fórmulas y conceptos que no desvirtúen, estigmaticen o criminalicen las etapas vitales, tanto para operadores jurídicos como no jurídicos, en este sentido, consideramos idóneos los conceptos de niñez o adolescencia ${ }^{31}$.

La actual norma que regula la responsabilidad penal de adolescentes en España, la Ley Orgánica 5/2000 de 12 de enero, Reguladora de la Responsabilidad Penal de los Menores, (LORPM), como su nombre indica es continuadora de la terminología escogida en el siglo pasado.

\subsubsection{Chile}

El contexto histórico chileno guarda semejanzas con lo apuntado para el Estado de Illinois y España, en el sentido de que las primeras regulaciones que se hicieron sobre infancia como indica Zorrilla citada por Luisa Schonhautd, proyectaban por un lado una imagen de compasión y, como contraparte, aseguraba la reclusión de estos "hijos del pecado, producto que bien se podía descuidar, considerados por la aristocracia una amenaza para la sociedad"32.

Realizando un breve apunte histórico, en 1901 se presenta por Malquías Concha un proyecto de reglamentación del trabajo que, entre sus disposiciones relacionadas con la infancia, propuso la prohibición de que "niños realicen trabajos penosos superiores a sus fuerzas". En 1912 se aprueba la Ley de Protección de la Infancia Desvalida, que como nos indica Luisa Schonhautb marcó el inicio de una política estatal de resguardo de menores en riesgo social. Pese a que entre sus bases destacó el control del abandono y de algunas formas de explotación, su aplicación fue marginal, centrada fundamentalmente en la reclusión de la niñez considerada vaga y/o delincuente. En 1928, se promulga la Ley de Menores, que teóricamente estaba orientada al amparo de los "más vulnerables, promoviendo el derecho al cuidado físico, a la educación, a la consideración social a mantener y desarrollar la propia personalidad y el derecho a la alegría"33. De esta normativa es necesario destacar dos cosas, en primer lugar, estas normas están relacionadas con sus precedentes asistenciales, la Casa del Niño de 1761 y las 10 medidas de 1892 de Olivares Muñoz preocupadas por disminuir la mortandad infantil -que alertan de entre otras problemáticas de la industria de las nodrizas mercenarias, preocupación que también se regula en España en 1904-. Entre otras normas e instituciones. En segundo lugar, decir que el cuidado de la infancia abandonada era asumido por obras de caridad religiosas y la filantropía de la elite aristocrática (como en Illinois) las que, por un lado, proyectaba una imagen de compasión y, como contraparte, aseguraba la reclusión de estos hijos del pecado, considerados por lo demás una amenaza para el orden social. Estas vidas en su niñez o juventud serán tutorizadas, reprimidas, castigadas y excluidas en aras a mantener el orden social, pero para poder gozar de estos "privilegios" eran necesarios dos requisitos. Por un lado, ser bautizado, es decir, solo se acogían a personas que fueran o se convirtiesen al catolicismo, no se educará ni se procesará ningún otro credo. Esto implica una negación y aniquilación de las diversas culturas y pueblos indígenas. El segundo requisito consistía en una certificación de abandono, sin derecho a ser reclamado, lo que otorgaba la facultad de borrar la historia, eliminar la identificación e incluso trucar el nombre de esa personita ${ }^{34}$.

31 El legislador español en aras al interés del superior nos habla en su legislación de medidas, y no de penas, sin embargo, no es crítico con el empleo del concepto menor, produciéndose a mi modo de ver una cierta contradicción.

32 Cfr. Schonhaut (2010), p. 306.

33 Ibid.

34 Ibid. Crf. p. 307.

FERNÁNDEZ MíGUEZ, Sheila. Cuestionando el sujeto estándar en derecho: análisis crítico de los conceptos minoría y mayoría de edad, niño, menores y adolescentes. Revista Justicia y Derecho, Santiago, v. 1, n 1, 2018 
Es necesario tener presente que, en Chile, la legislación cuando hacía referencia expresa al cuerpo de las niñas o jóvenes, no era para castigarlas o protegerlas, sino para garantizar los derechos de otros. En las familias blancas eran consideradas mercancía y las indígenas, negras o mestizas fueron deliberadamente desprotegidas. En este sentido Salazar afirma la existencia de "la tolerancia abierta respecto del acceso sexual a mujeres (solteras menores de edad) negras, indígenas o mestizas, tanto en relaciones formalmente consensuales como abiertamente coaccionadas, como era el caso de las niñas que trabajaban como criadas en casas patronales y eran forzadas, con cierta frecuencia, a prestar servicios sexuales ${ }^{35}$, es decir estas niñas y adolescentes (mujeres) podían ser violadas por hombres blancos que resultaban impunes.

Si bien, como se ha indicado, el primer concepto para referirse a esta franja etaria en el ámbito legal fue el término niño ${ }^{36}$ vinculado con la idea de protección, (Casa Nacional de Niño), los conceptos por los que se decanta el legislador en cada momento histórico van cambiando. Fijándonos en algunas de las normas que contienen disposiciones penales, vemos como la Ley 2.675, de 4 de septiembre de 1912, de Protección de la Infancia Desvalida ${ }^{37}$, es la primera norma promulgada con el objetivo de resolver el problema del abandono paterno ${ }^{38}$, el abuso de menores y algunas formas de explotación. Su aplicación fue muy discreta, pero contribuyo a marcar el inicio de una política estatal orientada hacia los niños en "riesgo social". Esta ley incluye también normas de protección además de las penales. Terminológicamente ocupa los conceptos de hijos, menores e impúberes. La Ley 4.447, de 23 de octubre de 1928, Sin Título, conocida como Ley de Menores ${ }^{39}$, sufre varias modificaciones, y actualmente está en vigor. En ella definitivamente el legislador escoge para la regulación el concepto menor. La norma está impregnada de un espíritu correccional-paternalista, como ponen de manifiesto su artículo 1 cuando habla del cuidado personal, la educación intelectual y profesional de los menores. O en el artículo 2, cuando establece la obligatoriedad de las materias de moral e higiene ${ }^{40}$. En el contexto actual, la terminología empleada por la legislación chilena nos habla de adolescentes o justicia juvenil, como se recoge en la Ley 20.084 de Responsabilidad Penal del Adolescente, de 7 de diciembre de 2005 (en adelante LRPA) ${ }^{41}$, en la misma se observa un cuidado en la selección de los conceptos por el legislador, tratando de escapar de la estigmatización de la expresión menores y decantándose por hablar de adolescentes. Muestra de ello es que en el artículo 2, se establece el interés superior de adolescentes, haciendo una construcción propia del interés superior del niño (niñas y niñes) que menciona la CDN. Sin embargo, el concepto "menores", todavía sigue muy presente en la cultura jurídica chilena, como ejemplo indicar, que en el ámbito civil y de protección existen los Tribunales Letrados de Menores.

La LRPA se articula en torno al concepto de adolescentes, término no jurídico, y que carece de la carga peyorativa que encontramos en niño y menores. Además, este concepto, tiene la ventaja de poder emplearse de forma inclusiva en cuanto al género, por lo que su uso resulta más adecuado. A pesar de la terminología escogida por la ley y las ventajas que sobre la misma entendemos que existe, advertimos

35 Cfr. la cita es referenciada en Couso (2009), p. 3.

36 En el ámbito social, existían previamente La Casa de Expósitos de Santiago, pero en atención al estigma que creaba ese nombre, pasó a denominarse La Casa Nacional del Niño.

37 Destacar también, que la ley no establece ninguna diferencia para niños y niñas (no existe el concepto de niñe en esta época). Sin embargo, sí establece tres franjas etarias, 8, 16 y 18 años. Para más información a este respecto, puede consultarse (en línea). Disponible en http://www.memoriachilena.cl/602/w3-article-95303.html [fecha de consulta: 18.07.2016].

38 Se refiere la ley en su artículo 1, al derecho al abandono que permitía el inciso segundo del Código Civil, de 1855.

39 "Que se orientó al amparo de los más vulnerables, promoviendo el derecho al cuidado físico, la educación, a la «consideración social», a mantener y desarrollar la propia personalidad y el derecho a la alegría" (Rojas J, en Luisa Schonhautb (2010), p. 306).

40 Crf. Ley 4.447, de 23 de octubre de 1928 (en línea). Disponible en http://www.leychile.cl/Navegar?idNorma=24742 [fecha de consulta: 18.07.2016].

41 Ley 20.084, de 7 de diciembre de 2005, de Responsabilidad Penal del Adolescente (en línea). Disponible en http://www. leychile.cl/Navegar?idNorma=244803 [fecha de consulta: 18.07.2016].

FERNÁNDEZ MíGUEZ, Sheila. Cuestionando el sujeto estándar en derecho: análisis crítico de los conceptos minoría y mayoría de edad, niño, menores y adolescentes. Revista Justicia y Derecho, Santiago, v. 1, no 1, 2018 
como parte de la doctrina chilena está adoptando el concepto "menores". Esta tendencia puede deberse a la influencia de los Convenios y Resoluciones de la ONU en algunas de sus traducciones al español y de la doctrina española y anglosajona, esta última pionera en estudios sobre la infancia, donde se emplea de forma habitual el concepto minor y se traduce al castellano como menores. En este sentido, estas traducciones comienzan a formar parte de las investigaciones chilenas que adoptan el concepto sin cuestionárselo, priorizando quizás, normas de economía de lenguaje, que en este caso pueden invisibilizar la pluralidad de personas y no son fieles a la realidad.

\subsubsection{Traducción de Convenios y Tratados Internacionales}

La aproximación, aunque breve al plano internacional permite observar con claridad como el derecho y los debates sobre niñez y adolescencia evolucionan desde la consideración de las niñas, niñes y niños como objetos de protección, a sujetos de derechos al igual que cualquier persona adulta, es decir la consideración de todas las personas como seres humanos ${ }^{42}$. Desde 1883 cuando se realiza el Primer Congreso Internacional de Protección a la Infancia, celebrado en París, 1913 el tema se va a fijar en los foros internacionales creándose una cultura común ${ }^{43}$. Como fruto de este trabajo se aprueba en 1924 la Declaración de Ginebra sobre los Derechos del Niño, y ya en 1959 la Sociedad de Naciones, precedente de Naciones Unidas (en adelante ONU) aprobó la Declaración de los Derechos del Niño. Ya en el marco de la ONU, se han aprobado entre otras normas, en 1985 las Reglas Mínimas para la Administración de Justicia de Menores (Reglas de Beijín), la Convención de los Derechos del Niño en 1989, las Directrices para la prevención de la delincuencia juvenil (Directrices de Riad) ${ }^{44}$ de 1990, y las Reglas de Naciones Unidas para la Protección de los menores privados de libertad también de $1990^{45}$. De lo expuesto, se puede apreciar también como en el plano internacional aparecen los mismos conceptos que en el estatal, y tanto el concepto niño como menores son empleados en diferentes Convenios.

A continuación, se expone la problemática que se genera en relación a las traducciones de los textos internacionales, analizando las Reglas de Beijín, pertenecientes al marco jurídico que establece las Naciones Unidas, y ello porque resultan de aplicación tanto para Chile como para España.

Llama la atención que, a pesar de que Chile y España comparten idioma, la Resolución 40/33, de 28 de noviembre de 1985 de la ONU, conocida como "Reglas de Beijing", ha sido traducida en ambos países de forma diferente. En España como Reglas de las Naciones Unidas para la Administración de la Justicia de Menores, y en el contexto chileno y latinoamericano se denomina Reglas Mínimas de las Naciones Unidas para la Administración de la Justicia Juvenil ${ }^{46}$. Denominación que también encontramos en el Observatorio Internacional de Justicia Juvenil ${ }^{47}$. Por otro lado, es significativo que las resoluciones y diferentes tratados de la ONU mezclan también ambos conceptos, hablándose de menores y justicia juvenil indistintamente, lo que en algunos supuestos puede generar ciertas dudas. Entendemos que esto es así,

\footnotetext{
42 Véase, Dávila y Naya, ob. cit., p. 73.

43 Cfr. Rollet, citado por Dávila y Naya, ob. cit., p. 73.

44 Directrices de las Naciones Unidas para la prevención de la delincuencia juvenil (Directrices de Riad). Adoptadas y proclamadas por la Asamblea General en su resolución 45/112, de 14 de diciembre de 1990 (en línea). Disponible en http://www. ohchr.org/SP/Professionallnterest/Pages/PreventionOfJuvenileDelinquency.aspx

45 Reglas de las naciones Unidas para la protección de los menores privados de libertad. Adoptadas por la Asamblea General en su resolución 45/113, de 14 de diciembre de 1990 (en línea). Disponible en https://www.cidh.oas.org/PRIVADAS/reglasnacionesunidasmenores.htm [fecha de consulta: 01.08.2016].

46 Cfr. Galiano Maritan, Grisel(2012): "La convención de los derechos del niño como tratado de derechos específicos de la niñez y la adolescencia", en Contribuciones a las Ciencias Sociales, marzo 2012. Disponible en www.eumed.net/rev/cccss/19/

47 Observatorio Internacional de Justicia Juvenil. Disponible en http://www.oijj.org/es/preguntas-frecuentes
}

FERNÁNDEZ MíGUEZ, Sheila. Cuestionando el sujeto estándar en derecho: análisis crítico de los conceptos minoría y mayoría de edad, niño, menores y adolescentes. Revista Justicia y Derecho, Santiago, v. 1, n 1, 2018 
ya que recuérdese, que menores serían todas aquellas personas con edad inferior a 18 años, según la CDN. Sin embargo, la justicia juvenil, se aplicaría en principio, para aquellas personas de 14 a 18 años. Si bien se incentiva en los textos internacionales ampliar esta edad hasta los 21 años, mandato que recogía la LORPM en su primera redacción. Esta variación terminológica añade una dificultad a mayores al ya complejo entramado normativo.

\subsection{Adolescentes}

Según el Diccionario de la lengua española, el adjetivo "adolescentes", se refiere a aquellas personas que están en la adolescencia ${ }^{48}$. En este sentido, es necesario conocer qué implica estar en la adolescencia; si acudimos nuevamente a la RAE, nos indica que es aquel periodo de tiempo que sigue a la niñez y precede a la juventud ${ }^{49}$, y como hemos indicado, estas franjas etarias no son conceptos pacíficos, y especialmente en el ámbito de la psicología se discute qué características tiene cada fase vital, que también están marcadas por el lugar de crianza y la personalidad entre otros factores. Dupret siguiendo a la RAE define adolescencia como la etapa transitoria de la vida entre la niñez y la adultez, pero lo hace de forma crítica, mencionando lo complejo que es hoy entender qué es ser adolescente o joven y las características de estos grupos ${ }^{50}$.

En Derecho se ha tratado de fijar una cifra para cada periodo vital. En el caso de la legislación chilena se establece una escala de acceso al ejercicio de los derechos basada en el binomio hombre-mujer en torno a la correspondencia única entre sexo-género y la capacitación gradual establecida desde el poder adulto. De los 0 a los 7 años, las personas son infantes e incapaces absolutas. De 7 a 12, las mujeres, y de 7 a 14, los hombres son impúberes, y se mantiene la incapacidad absoluta. La siguiente franja para las mujeres se inicia en los 12 años y para los varones 14, donde la incapacidad es relativa ${ }^{51}$. Es necesario tener en cuenta que en Derecho penal existe una graduación propia. Así la Ley 19.968, de 30 de agosto de 2004, que Crea los Tribunales de familia, en su art. 9 establece que serán competentes estos tribunales para todos los asuntos que se impute la comisión de cualquier falta a adolescentes mayores de catorce y menores de dieciséis años de edad, y las que se imputen a adolescentes mayores dieciséis y menores de dieciocho años, que no se encuentren contempladas en el inciso tercero del artículo $1^{\circ}$ de la ley $n^{\circ}$ 20.084. Por lo tanto, si bien el derecho chileno gradúa el acceso a derechos/capacidades en el área civil y diferencia entre los procesos de maduración de uno y otro género, no sigue el mismo criterio en derecho penal, donde desde los catorce años se es responsable por los hechos cometidos (art. 10.2 CP chileno). La única consideración que hace el legislador es relativa al órgano juzgador, Tribunales de Familia de 14 a 16, y de 16 a 18 años. Sin embargo, ante determinadas faltas, las indicadas en el amplio catálogo del art. 1 de la Ley 20.084, las personas de dieciséis a dieciocho años serán juzgadas por tribunales penales.

La legislación española también gradúa el tránsito de la incapacidad a la capacidad en el ámbito civil pero no establece en la actualidad diferencia entre sexo-género. En el ámbito penal la responsabilidad es a partir de los 14 años a los 18 años, existiendo un procedimiento especial y Tribunales especiales, denominados Juzgados de Menores, regulados también, en la citada ley de 5/2000, de 12 de enero, Reguladora de la Responsabilidad Penal de los Menores (en adelante LORPM).

48 Cfr. Diccionario de la Lengua española. Disponible en http://dle.rae.es/?id=0nrRMdF [fecha de consulta: 25.07.2016].

49 Ibi. Disponible en http://dle.rae.es/?id=0nrQ4BH [fecha de consulta: 25.07.2016].

50 Cfr. Dupret (2010), p. 72.

51 Véase, Libertad y Desarrollo (2012): "Revisión de la legislación vigente: Menores en Chile: ¿Cuándo son o no son capaces?", pp. 1-10. Disponible en http://lyd.org/wp-content/uploads/2012/02/CAPACIDAD-DE-MENORES.pdf [fecha de consulta: 27.09.2016].

FERNÁNDEZ MíGUEZ, Sheila. Cuestionando el sujeto estándar en derecho: análisis crítico de los conceptos minoría y mayoría de edad, niño, menores y adolescentes. Revista Justicia y Derecho, Santiago, v. 1, n 1, 2018 


\section{Derechos sexuales y Reproductivos. El tratamiento legal de la Capacidad en LA MINORÍA DE EDAD}

Las categorías conceptuales presentadas anteriormente y las edades de incapacidad son objeto controvertido en la bibliografía en la que encontramos diferentes teorías para justificar la restricción o el acceso a los derechos. Mientras las primeras conocidas como Teorías Positivistas-Paternalistas apelan al control y restricción de derechos, y han estado y están, como se ha expuesto, en la planificación y articulación de políticas gubernamentales, las segundas, genéricamente denominadas Teorías Liberacionistas de los Derechos, consideran que la infancia es una construcción social, que proyecta a la niñez como grupo oprimido que no tiene capacidad para ejercitar sus derechos y carece de autonomía. Mónica González Contró indica que se despoja a estas personas de sus derechos reales, de la misma manera que durante siglos se creyó que las personas negras o las mujeres eran naturalmente inferiores y por lo tanto incapaces de compartir la titularidad de derechos con los varones blancos. El origen de esta supuesta inferioridad de la niñez surge de los prejuicios de los grupos dominantes, por ello, es necesario liberar a la niñez al igual que se ha hecho con otros colectivos y esta emancipación sólo podrá realizarse a través de permitirles la toma de decisiones autónomas ${ }^{52}$.

En esta línea, pero introduciendo la variable de clase, en 1969 Kate Millett en su Tesis Doctoral por la Universidad de Columbia, titulada Sexual Politics, afirma que el problema "es que existe una situación de explotación entre las personas adultas y la infancia de la misma forma que existe entre los hombres y las mujeres, las relaciones intergeneracionales tienen lugar en una situación de desigualdad"y plantea que parte de la estructura de la familia patriarcal comprende el control de la vida sexual de la infancia y más allá, el control total y del dinero, lo cual, en una economía de dinero, es una de las principales fuentes de su opresión ${ }^{53}$; esta opresión se ejerce desde el poder adulto, concepto acuñado por Millett.

Un ejemplo de lo anterior en la legislación actual española, es el control/regulación de la vida afectivo sexual y reproductiva que se hace desde el Derecho y en especial desde el Derecho Penal. Me interesa destacar el caso de España, porque considero se ha producido un retroceso en relación a los derechos sexuales y reproductivos de personas adolescentes, que particularmente perjudica a las mujeres, a través especialmente de tres recientes normas: la Ley Orgánica 1/2015, de 30 de marzo, por la que se modifica la Ley Orgánica 10/1995, de 23 de noviembre, del Código Penal; la Ley 15/2015, de 2 de julio, de la Jurisdicción Voluntaria y la Ley Orgánica 11/2015, de 21 de septiembre, para reforzar la protección de las menores y mujeres con capacidad modificada judicialmente en la interrupción voluntaria del embarazo. Todas estas reformas legales datan del año 2015 y coinciden con un gobierno central del Partido Popular de ideología conservadora. Trataremos brevemente a continuación tres derechos a los que se ha limitado o restringido el acceso: la edad para contraer matrimonio, para consentir relaciones sexuales y la capacidad para autorizar una interrupción voluntaria del embarazo.

En España podían contraer matrimonio personas adolescentes previa dispensa judicial desde los 14 años (antiguo art. 48 del CCE ${ }^{54}$ del año 1981). Como es conocido, las relaciones sexuales son inherentes a dicha institución, de hecho, la ausencia de las mismas era causa para solicitar la nulidad matrimonial en sede católica. Podemos considerar entonces, que el legislador reguló las prácticas sexuales y la familia

52 González (2006), pp. 101-136.

53 Cfr. Pudelo, Alicia(2010): "Lo personal es político: el surgimiento del feminismo radical", en Mujeres en Re. Disponible en http://www.mujeresenred.net/spip.php?article2061 ]fecha de consulta: 26.07.2016].

54 La redacción del artículo a la que se hace referencia se recoge en la Ley 30/1981, de 7 de julio, por la que se modifica la regulación del matrimonio en el Código Civil y se determina el procedimiento a seguir en las causas de nulidad, separación y divorcio. Disponible en https://www.boe.es/diario_boe/txt.php?id=BOE-A-1981-16216 [fecha de consulta: 27.07.2016].

FERNÁNDEZ MíGUEZ, Sheila. Cuestionando el sujeto estándar en derecho: análisis crítico de los conceptos minoría y mayoría de edad, niño, menores y adolescentes. Revista Justicia y Derecho, Santiago, v. 1, n 1, 2018 
para adolescentes, desde los 14 años. Sin embargo, con la aprobación de la Ley 15/2015, de 2 de julio, de la Jurisdicción Voluntaria, solo podrán contraer matrimonio las personas mayores de 16 años y que estén emancipadas. Esta reforma se justifica con el argumento de la protección de los niños, niñas (y niñes), de la pederastia y matrimonios forzados, pero si analizamos las cifras, en el año 2014, solo se han celebrado cinco matrimonios de personas menores de edad55, de los cuales no hay ninguno de personas de 14 años, y solo uno corresponde a personas de 15 años ${ }^{56}$ lo que nos indica que no hay un peligro real de matrimonios forzados en España.

En relación con la edad para consentir relaciones sexuales, el Código penal español, después de la reforma de la citada L.O. 1/2015, en su artículo 183 primero, indica lo siguiente: el que realizare actos de carácter sexual con un menor de dieciséis años, será responsable de abuso sexual a un menor con la pena de prisión de dos a seis años57. El artículo tipifica las relaciones sexuales con personas menores de 16 años, solo por el hecho de ser menores de 16 años. Según el preámbulo de la L.O. 1/2015, párrafo XII, el legislador indica que viene a cumplir con las recomendaciones de organismos internacionales y la propia legislación de la Unión Europea, en concreto la Directiva 2011/93/UE ${ }^{58}$. En este sentido, es necesario precisar, que tanto las citadas recomendaciones como la directiva no fijan la edad, sino que solo recomiendan su incremento, dejando a los legisladores estatales la capacidad de fijar dicha edad. El legislador español modificó de 13 años a 16 años la edad de consentimiento, incrementando en 3 años la edad para consentir relaciones sexuales.

Es necesario evaluar si este incremento se corresponde con la realidad de la juventud española. En este sentido el estudio Relaciones afectivas y sexualidad en la adolescencia, realizado por la Liga Española de Educación, publicado en el 2014, indica que desde los 13 años hay adolescentes que se inician en las prácticas sexuales, si bien la edad más habitual son los 14 y 15 años, confirmándose la tendencia a iniciar cada vez más temprano las relaciones sexuales. Según recoge el informe, en los últimos cincuenta años la edad media de la primera relación sexual ha disminuido 5,6 años ${ }^{59}$. En este sentido, si las prácticas sexuales se desarrollan desde los 13 años, entonces es necesario preguntarse qué sucede con las personas menores de edad que tienen relaciones con personas menores de edad o mayores de edad. Para ello, el legislador establece una excepción a la regla general en el preámbulo, indicando que no se considerará hecho delictivo si se trata de relaciones consentidas con una persona próxima al menor por edad o grado de desarrollo o madurez60. Esta indicación deja por tanto al criterio del juzgado o tribunal la valoración

55 Lillo, Sergio: "Los menores de 16 años ya no podrán casarse en España” en El País (en línea). Disponible en http://politica. elpais.com/politica/2015/07/15/actualidad/1436947148_829261.html [fecha de consulta: 27.07.2016].

56 Cfr. Instituto Nacional de Estadística de España (INE). Disponible en http://politica.elpais.com/politica/2015/07/15/actualidad/1436947148_829261.html [fecha de consulta: 27.07.2016].

57 La regulación de las relaciones sexuales con personas menores de edad se encuentra recogida a lo largo de los artículos 178 y ss., del CP español. Interesa destacar el artículo 183, porque claramente establece la diferencia para las relaciones sexuales con personas menores de dieciséis, por lo que a partir de dieciséis se será libre para consentir. El problema se puede plantear entre que sucede si una persona tiene 14 y la otra 16 o 17. Es a través de la modificación de este artículo, siguiendo recomendaciones y con la trasposición de la Directiva 2011/93/UE, relativa a la lucha contra los abusos sexuales y la explotación sexual de los menores y la pornografía infantil, y por la que se sustituye la Decisión Marco 2004/68/JAl del Consejo, que se incrementa dicha edad. 58 Cfr. Directiva 2011/92/UE Del Parlamento y del Consejo de 13 de diciembre de 2011, relativa a la lucha contra los abusos sexuales y la explotación sexual de los menores y la pornografía infantil y por la que se sustituye la Decisión marco 2004/68/ JAI del Consejo, si bien no determinan la edad de consentimiento sexual, sí indica en su artículo 2 que ha de entenderse por "edad de consentimiento sexual", aquella edad por debajo de la cual, de conformidad con el Derecho nacional, está prohibido realizar actos de carácter sexual con un menor (en línea). Disponible en http://eur-lex.europa.eu/legal-content/ES/TXT/?uri=CELEX\%3A32011L0093 [fecha de consulta: 27.07.2016].

59 Cfr. Delfino Goicochea, Maria Antonienta (dir.) (2013): Relaciones afectivas y sexualidad en la adolescencia. Informe de la Liga Española de la Educación, financiado por el Gobierno de España. Ministerio de Sanidad, Servicios Sociales e lgualdad, p. 40.

60 Cfr. Ley Orgánica 1/2015, de 30 de marzo, por la que se modifica la Ley Orgánica 10/1995, de 23 de noviembre, del Código Penal, en Boletín Oficial del Estado, no 77, martes 31 de marzo de 2015, sec. I. p. 27.070 (en línea). Disponible en https://www.boe.

FERNÁNDEZ MíGUEZ, Sheila. Cuestionando el sujeto estándar en derecho: análisis crítico de los conceptos minoría y mayoría de edad, niño, menores y adolescentes. Revista Justicia y Derecho, Santiago, v. 1, no 1, 2018 
de la relación y las personas, para determinar si existe o no hecho delictivo, lo que introduce un grado de inseguridad jurídica. Y conviene recordar que las relaciones sexuales en las que mediase algún grado de acoso, intimidación o violencia ya se encontraban tipificadas.

En el caso chileno se pueden consentir relaciones desde los 12 años, siempre que no exista distancia de más de tres años con la otra persona, produciendo la normativa una serie de casuística contradictoria y difícil de resolver ${ }^{61}$. Sin embargo, esta edad de consentimiento solo opera para las relaciones heterosexuales, prohibiendo el articulo 365 CPCh las relaciones lésbicas y homosexuales juveniles ${ }^{62}$.

En relación a la interrupción voluntaria del embarazo, la L.O 2/2010, de 3 de marzo, de salud sexual y reproductiva y de la interrupción voluntaria del embarazo, que modificó el régimen legal relativo al aborto en España, permite a las adolescentes realizarse una IVE. Estableciendo los requisitos que las adolescentes deberían cumplir en su artículo 13, relativo a los requisitos comunes para la interrupción voluntaria del embarazo, contenía un apartado cuarto que recogía lo siguiente:

En el caso de las mujeres de 16 y 17 años, el consentimiento para la interrupción voluntaria del embarazo les corresponde exclusivamente a ellas de acuerdo con el régimen general aplicable a las mujeres mayores de edad.

Al menos uno de los representantes legales, padre o madre, persona con patria potestad o tutores de las mujeres comprendidas en esas edades deberá ser informado de la decisión de la mujer.

Se prescindirá de esta información cuando la menor alegue fundadamente que esto le provocará un conflicto grave, manifestado en el peligro cierto de violencia intrafamiliar, amenazas, coacciones, malos tratos o se produzca una situación de desarraigo o desamparo.

Sin embargo, este apartado fue suprimido por el artículo primero de la L.O. 11/2015, de 21 de septiembre, para reforzar la protección de las menores y mujeres con capacidad modificada judicialmente en la interrupción voluntaria del embarazo, que entró en vigor el 23 de septiembre de 2015. Esto ha significado que las adolescentes que viven una situación de violencia, como indicaba el último apartado del artículo 13.4, y que no desean llevar a término un embarazo, porque bien no quieren ejercer la maternidad, ni tampoco quieren entregar en adopción a su bebe, han quedado sin protección por parte del legislador, dejando como única alternativa la vía judicial para que puedan acceder a una IVE, produciéndose bajo mi punto de vista una violencia del estado sobre estas mujeres.

Es necesario conocer los datos sobre IVES adolescentes en España, para contextualizar la dimensión de esta realidad. El Instituto Nacional de Estadística (en adelante INE), en datos correspondientes al año 2014, indica que en España se produjeron 94.796 IVE, de las cuales, 3.239 corresponden a mujeres de entre 12 a 17 años, es decir, el 3,41\% de las IVE que se realizaron en España, son en mujeres menores de edad. La cifra que nos interesa desvelar es cuantas, de estas mujeres, se han practicado una IVE sin informar a su familia o tutores legales. Este dato es una cifra negra, dado que el INE no la facilita, lo más aproximado que se puede encontrar para el periodo enero-septiembre de 2014, son las cifras de la Asociación de Clínicas Acreditadas para la Interrupción Voluntaria del Embarazo (ACAI) ${ }^{63}$, que indica que de

es/boe/dias/2015/03/31/pdfs/BOE-A-2015-3439.pdf [fecha de consulta: 28.07.2016].

61 Véase para más información al respecto, Couso, Jaime (2009): "La sexualidad de los menores de edad ante el Derecho penal". SELA (Seminario en Latinoamérica de Teoría Constitucional y Política) Papers. Paper 73.

62 Véase para más información al respecto, Bascuñán (2011), pp. 113-137.

63 Asociación de Clínicas Acreditadas para la Interrupción voluntaria del embarazo, Mujeres de 16 y 17 años que no han podido comunicar a sus padres o tutores la interrupción de su embarazo, España: Investigación ACAl, 2014, p. 5 (en linea). Disponible en http://www.acaive.com/pdf/Investigacion-ACAhttp://www.acaive.com/pdf/Investigacion-ACAl-menores-16-y-17-anos-noviembre-2014.pdfl-menores-16-y-17-anos-noviembre-2014.pdf [fecha de consulta: 27.09.2016].

FERNÁNDEZ MíGUEZ, Sheila. Cuestionando el sujeto estándar en derecho: análisis crítico de los conceptos minoría y mayoría de edad, niño, menores y adolescentes. Revista Justicia y Derecho, Santiago, v. 1, n 1, 2018 
las adolescentes de 16 y 17 años que se han practicado una IVE, en este periodo son 913, de las cuales solo 113 mujeres se acogieron al apartado 4 del artículo 13 de la ley, es decir 12,38\% de las adolescentes que interrumpen su embarazo se encuentran en una situación de vulnerabilidad en su entorno familiar. Esta cifra supone un 0,44\% sobre el total de abortos para este periodo que fue de 25.394. A la luz de estas cifras, se aprecia como existe la necesidad para un grupo reducido de mujeres de contar con esta posibilidad y protección por parte del Estado y no se justifica la supresión de este derecho por parte de la norma L.O. 11/2015, que responde a las creencias ideológicas de un sector político.

En Chile está penalizado el aborto en los artículos 342 al 345 del CPCh, especial relevancia para la autodeterminación de la mujer tiene el artículo 344, que persigue a la mujer que se produce un aborto o consiente que otra persona se lo realice. Y el articulo 345 CPCh penaliza al facultativo sanitario que realiza un aborto. De esta regulación cabe concluir que en Chile todos los supuestos de aborto conllevan una pena de prisión y hasta la fecha incluso para niñas gestantes como consecuencia de violaciones incestuosa, el estado se ha negado a que estas niñas pudiesen acceder a una IVE. En la actualidad se discute un proyecto de ley de tres causales, que pretende hacerse cargo de la recomendación del año 2004 del Comité de Derechos Económicos, Sociales y Culturales que instaba al Estado de Chile a revisar su "legislación y despenalizar el aborto cuando se trate de abortos terapéuticos y cuando el embarazo sea consecuencia de violación o incesto"64.

\section{Conclusiones}

A la luz de lo expuesto, las principales conclusiones a las que podemos llegar son tres. En primer lugar, indicar que a pesar de que la legislación establece un acceso al ejercicio de los derechos y la exigencia de responsabilidades, basada en una capacitación gradual, esto no siempre se cumple. Uno de los principales problemas que enfrentan las personas durante la niñez o adolescencia es que no se regulan sus derechos y, por lo tanto, no pueden hacer uso de los mismos; o cuando están contemplados en los marcos normativos estatales los Estados no los respetan, por lo que existe un problema grave de acceso a la justicia para este colectivo. En este contexto, es necesario tener en cuenta que las personas de diferente etnia que la dominante, condición de diversidad funcional, de la diversidad sexual, o con situación administrativa irregular, son personas no ciudadanas -en el sentido de que no gozan de los mismo derechos que una persona heterosexual nativa-, o menos ciudadanas en los actuales Estados, independientemente de los años de edad, colocando a estos grupos en una grave situación de riesgo y conflicto social a la par que de vulneración de derechos humanos. Esta situación se agrava si la persona que pertenece a estos grupos sin poder es menor de 18 años, al recaer sobre ella una suerte de regulación protectora y criminal, padeciendo por el hecho de ser joven lo que podemos considerar una doble opresión, la que sufre el grupo en general, fruto de normativas discriminatorias, y la concreta por el hecho de ser joven, colectivo políticamente no empoderado.

En segundo lugar, hay que destacar que tanto la legislación chilena como la española, pueden encuadrarse dentro de las Teorías Positivistas y Paternalistas e implantan un modelo correccional. Las mismas forman parte de la estructura patriarcal y adultocéntrica. Ejemplo claro de ello es el uso que se hace del Derecho Penal, configurado como instrumento de ultima ratio, para imponer un modelo sexual y

64 Mensaje de S. E. la presidenta de la República con el que se inicia un proyecto de ley que regula la despenalización de la interrupción voluntaria del embarazo en tres causales, de 31 de enero de 2015, p. 13 (en línea). Disponible en http://3causales. gob.cl/proyecto-de-ley/ [fecha de consulta: 27.09.2016].

FERNÁNDEZ MíGUEZ, Sheila. Cuestionando el sujeto estándar en derecho: análisis crítico de los conceptos minoría y mayoría de edad, niño, menores y adolescentes. Revista Justicia y Derecho, Santiago, v. 1, n 1, 2018 
reproductivo que se implanta desde un poder adulto heteronormativo, y que coloca como incapaces a adolescentes, restringiendo su derecho al libre desarrollo y a la autonomía, vulnerando lo establecido en la CDN.

Y, en tercer lugar, comprobamos cómo detrás de cada Teoría sobre la gestión de la vida se encuentra un discurso implícito en la terminología empleada, que los conceptos no son pacíficos en sí. Es necesario, por tanto, seguir avanzando cara una regularización de la sexualidad libre y consentida. Y la (de) construcción de este modelo normativo que estigmatiza y criminaliza, desde la propia terminología a la niñez y adolescencia. Para lograr lo indicado, urge una rigurosa revisión de la historia para una acertada representación de la realidad y la construcción de sistemas jurídicos integradores y respetuosos con los Derechos Humanos. Esta revisión ha de ir acompañada de un análisis sobre el discurso del lenguaje, pues como indicaba Foucault "en toda sociedad la producción del discurso está a la vez controlada, seleccionada y restringida por un cierto número de procedimientos que tienen por función conjurar sus poderes" ${ }^{\prime \prime}$. Por ello, cualquier estudio, ha de partir de "concebir lo humano dentro de una estructura lingüística cultural que define de primeras la posición del sujeto en una serie de intercambios significantes ${ }^{\prime \prime 66}$. En este sentido, se ha tratado de ser coherente en el uso del lenguaje y apostar por conceptos como niñez, adolescencia o juventud que consideramos son los adecuados, por ser inclusivos en cuanto al género.

En las presentes líneas hemos tratado de conectar datos históricos, con la construcción y uso de lenguaje, con nuestra realidad actual jurídica y social, con el fin demostrar como la construcción del discurso en general y el jurídico en particular, son para las minorías en fase de empoderamiento, y en concreto para la niñez y adolescencia, un campo de batalla ideológica, un lugar que conquistar. Y para las ciencias y saberes sociales un punto desde el que repensar y construir con rigor y justicia.

\section{Bibliografía CitAda}

Asociación de Clínicas Acreditadas para la InterRupción voluntaria del embarazo, 2014. Mujeres de 16 y 17 años que no han podido comunicar a sus padres o tutores la interrupción de su embarazo, España, 2014.

Araiza Díaz, Alejandra (2012): "De la política de la localización a los conocimientos situados. Notas para la creación de una ciencia feminista" en Liévano Franco, Martha/ Duque Mora, Marina (coords.), Subjetivación femenina: investigación, estrategias y dispositivos críticos (Monterrey, México, Ediciones UANL, Colección Tendencias).

BASCUÑÁn, Antonio (2011): "La prohibición penal de la homosexualidad masculina juvenil”, Estudios Públicos, no124, pp. 113-137.

BAsCuñán, Antonio et al. (2013): “La inconstitucionalidad del artículo 365 del código penal. Informe en Derecho", Revista de estudios de la Justicia, no 14, pp. 73-109.

Brandariz García, José Ángel (2014): El gobierno de la Penalidad. La complejidad de la política criminal contemporánea (Madrid, Dykinson).

CABEZAS Salmeron, JoRdi (2011): "Superación del modelo anterior de justicia juvenil (tutelar) por el actual modelo (de responsabilidad). ¿Se lo ha creído alguien?", Revista Crítica de Penal y Poder, n¹, pp. 158-173.

Cámara Arroyo, Sergio (2011): "El Internamiento de las menores infractoras en España", Anuario de la Facul-

65 Cfr. Foucault (1995), p. 14

66 Cfr. HAINRICHSEN (2009), p. 145,

FERNÁNDEZ MíGUEZ, Sheila. Cuestionando el sujeto estándar en derecho: análisis crítico de los conceptos minoría y mayoría de edad, niño, menores y adolescentes. Revista Justicia y Derecho, Santiago, v. 1, n 1, 2018 
tad de Derecho de la Universidad de Alcalá IV, n4, pp. 335-337.

Cortina, Adela (2011): "Ciudadanía democrática: ética, política y religión. XIX Conferencia Aranguren", Isegoría. Revista de Filosofía Moral y Política, № 10, pp. 13-55.

Couso, JAImE (2009): "La sexualidad de los menores de edad ante el Derecho penal”. SELA (Seminario en Latinoamérica de Teoría Constitucional y Política) Papers. Paper 73, pp. 1-46.

Dávila Balsera, Paulí; Naya Gardemian, Luis María (2006): "La evolución de los derechos de la Infancia: Una visión Internacional", Encouters on Education, vol. 7, pp.71-93.

Delfino Goicochea, Maria Antonienta (dir.) Relaciones afectivas y sexualidad en la adolescencia. Informe de la Liga Española de la Educación. Gobierno de España. Ministerio de Sanidad, Servicios Sociales e Igualdad. 2013

Dupret, Marie-Astrid (2010): "Criminalización de la juventud margina”, Universitas. Revista de Ciencias Sociales y Humanas, no 13, julio-diciembre 2010, pp. 69-94.

Foucault, Michel (1995): La verdad de las formas jurídicas (Barcelona, Gedisa, 2a ed.).

Galiano Maritán, Grisel (2012): "La Convención de los Derechos del niño como Tratado de Derechos específicos de la niñez y la adolescencia. Máximo referente normativo de la cultura jurídica para la infancia", Contribuciones a las ciencias sociales, no 3, pp. 1-26.

GonzÁlez Contró, Mónica (2006): "Paternalismo jurídico y derechos del niño", Isonomía: Revista de teoría y filosofía del derecho, n²5, pp. 101-136.

Hainrichsen, Felipe Ramírez (2009): "SENAME ¿Protección o punición? Comentarios de su acción biopolítica y disciplinaria, Summa Psicológica UTS, 6 (2):146-45.

Hermida, Sanz, Ágata María (2002): El nuevo proceso penal del menor (Universidad de Castilla la Mancha, Ed. Castilla la Mancha).

Montero, Tomas. Justicia Juvenil: Instrumentos internacionales [en línea]. España: 2011 [fecha de consulta: 5 de abril 2016]

Rivera, AndRÉs (2015): "Derechos civiles de la población trans (transgénero, travesti, transexuales e intersex)" en Gauche, Ximena, Erazo, Ximena y Jara, José (eds), Derechos humanos, diversidad sexual y políticas públicas en América Latina (ed. Lom Ediciones), pp. 125-133.

Riveira BeIRAS, IÑak (2003): "Historia y legitimación del castigo. ¿Hacia dónde vamos?" en Bergallı, Roberto (coord. y colaborador), Sistema penal y problemas sociales (Valencia, Tirant Lo Blanch), pp. 84 -183.

Schonhaut, Luisa (2010): "Profilaxia del Abandono: Cien Años de Protección de la Infancia en Chile", Revista chilena de pediatría, vol. 81 n4, pp. 304-312.

Villarreal, Felipe y Vallejos, Alejandra (2015): "Niños, niñas y adolescentes diversos/as" en Gauche, Ximena, Erazo, Ximena y Jara, José (eds), Derechos humanos, diversidad sexual y políticas públicas en América Latina (ed. Lom Ediciones), pp.135-166.

\section{Normas citadas}

\section{Chile}

Ley 2.675 (4/9/1912), de Protección de la Infancia Desvalida. 
Ley 4.447 (23/10/1928), Sin Título, conocida como Ley de Menores.

Ley 19.221 (1/6/1993), que Establece mayoría de edad a los 18 años y modifica cuerpos legales que indica.

Ley 19.968 (30/8/2004), que Crea los Tribunales de familia.

Ley 20.032 (2/7/2005), que Establece sistema de atención a la niñez y adolescencia a través de la red de colaboradores del Sename, y su régimen de subvención.

Ley 20.084 (7/12/2005), que Establece un sistema de responsabilidad de los adolescentes por infracciones a la Ley Penal.

Decreto- 230 (12/8/2006), que Promulga el Convenio de Cooperación sobre asistencia a la niñez y a la adolescencia entre la República de Chile y la República de Ecuador.

Ley 20.558 (7/1/2012), que Establece el día del niño y niña prematuros.

Decreto 105 (14/8/2012), que Modifica Decreto No841, de 2005, que aprueba Reglamento de la Ley No 20.032, que establece un sistema de atención a la niñez y adolescencia a través de la red de colaboradores acreditados del servicio Nacional de menores, y su régimen de subvención.

Mensaje de S. E. la presidenta de la República con el que se inicia un proyecto de ley que regula la despenalización de la interrupción voluntaria del embarazo en tres causales, de 31 de enero de 2015.

Proyecto de Ley, Sistema de Garantías de los derechos de la niñez, de 24 de septiembre de 2015, Boletín 10315-18.

Proyecto de ley núm. 10784-07 de C. Diputados, de 5 de julio de 2016 (modifica el Código Penal para establecer la imprescriptibilidad de la acción penal y de la pena tratándose de delitos sexuales, de tráfico ilícito de migrantes y de trata de personas, cometidos contra menores de edad).

\section{España}

Real Decreto, de 24 de julio de 1889, por el que se publica el Código Civil.

Ley de Bases, de 2 de agosto de 1918 que regula la administración de justicia aplicada en la infancia y adolescencia.

Decreto Ley, de 25 de noviembre de 1918, de creación y funcionamiento de los Tribunales para Niños.

Real Orden, de 2 de enero de 1930, por la que se prohíbe la asistencia a menores de 14 años a toros y boxeo.

Ley $1 / 1977$, de 4 de enero, para la Reforma Política.

Real Decreto-Ley 33/1978, de 16 de noviembre, sobre mayoría de edad.

Real Decreto-ley 38/1978, de 5 de diciembre por el que, de acuerdo con la excelentísima Diputación Foral de Navarra.

Ley 30/1981, de 7 de julio, por la que se modifica la regulación del matrimonio en el Código Civil y se determina el procedimiento a seguir en las causas de nulidad, separación y divorcio.

Ley Orgánica 10/1995, de 23 de noviembre, del Código Penal.

Ley Orgánica 13/1995, de 18 de diciembre, sobre la modificación de la Ley Orgánica General Penitenciaria. 
Ley 1/1997, de 7 de febrero, de atención integral a los menores.

Orgánica 5/2000, de 12 de enero, Reguladora de la Responsabilidad Penal de los menores.

Ley 1/2006, de 28 de febrero, de Protección de Menores de La Rioja.

Ley 8/2008, de 20 de junio, de la Generalitat, de los Derechos de Salud de Niños y Adolescentes (Derogada).

Ley Orgánica 1/2015, de 30 de marzo, por la que se modifica la Ley Orgánica 10/1995, de 23 de noviembre, del Código Penal.

Ley 15/2015, de 2 de julio, de la Jurisdicción Voluntaria.

Circular 6/2015, de la Fiscalía, sobre aspectos civiles de la sustracción internacional de menores

Ley Orgánica 11/2015, de 21 de septiembre, para reforzar la protección de las menores y mujeres con capacidad modificada judicialmente en la interrupción voluntaria del embarazo.

\section{Internacional}

Resolución 40/33, de 28 de noviembre de 1985 de Naciones Unidas.

Resolución 44/25, de 20 de noviembre de 1989, de Naciones Unidas, conocida como, Convención Sobre los Derechos del Niño.

Directiva 2011/92/UE Del Parlamento y del Consejo de 13 de diciembre de 2011, relativa a la lucha contra los abusos sexuales y la explotación sexual de los menores y la pornografía infantil y por la que se sustituye la Decisión marco 2004/68/JAl del Consejo.

\section{Recursos Web}

Biblioteca del Congreso Nacional www.leychile.cl

Boletín Oficial de España (BOE) www.boe.es

Censo guía de archivos de España e Iberoamérica http://censoarchivos.mcu.es/CensoGuia/fondoDetail.ht$\mathrm{m} ? \mathrm{id}=810815$

Euro Lex. Acceso al Derecho de la Unión Europea http://eur-lex.europa.eu/homepage.html Instituto NaCiOnal de Estadística de España (INE) http://www.ine.es/welcome.shtml

LIBERTAD Y DESARROLlo http://www.lyd.com/centro-de-prensa/noticias/2012/02/menores-en-chile-\%C2\%BFcuando-son-o-no-son-capaces/

Oficina del Alto Comisionado de las Naciones Unidas para los Derechos Humanos http://www2.ohchr.org/

ObSERVATORIO InternaCIONAL DE JUsticia JuvenIL http://www.oijj.org/es/preguntas-frecuentes

Real Academia de la Lengua Española http://lema.rae.es/drae/?val=cr\%C3\%ADo 